\title{
My last tribute to a friend, a pioneer and legend-Dr. David John Sugarbaker (1953-2018)
}

On August 29, 2018, the thoracic surgical community throughout the world was shocked by the sad news that a legend suddenly left us. Dr. David John Sugarbaker (Figure 1) passed away in Texas after a long battle against liver cancer, something he was keeping very much to his family and close friends until that day.

Dr. Sugarbaker was born on August 5, 1953 in Jefferson City, Missouri to a medical family. His father, the late Dr. Everett Dornbush Sugarbaker (1910-2001), was a cancer surgeon, and so he had first-hand knowledge of medicine from his early years, which no doubt influenced his later career. He received his Bachelor of Science Cum laude in 1975 from Wheaton College, and graduated top of his class from Cornell University Medical School in 1979. He completed his general surgical residency at Brigham and Women's Hospital in Boston, and cardiothoracic surgical residency at Toronto General Hospital. Having completed his training, he returned to Brigham and Women's Hospital in 1988 as the first head of the then newly established thoracic surgery department which he subsequently turned into one of the premier thoracic surgical centres in the world.

He was the mentor of mentors and his contribution to the advancement of general thoracic surgery was legendary. He built the first non-cardiac division of thoracic surgery in the US at the Brigham and Women's Hospital (BWH). In 1992, he developed the first general thoracic surgical training track in the US and has since trained over eighty residents, and placed two-thirds of them into academic positions, many of whom subsequently became heads of department. His research interest in the management of malignant pleural mesothelioma (MPM) started in 1988, and quickly earned him an international reputation. In 2002, he established the International Mesothelioma Program which attracted patients from all over the world to go to him. He refined and popularized the tri-modality approach, extrapleural pneumonectomy and hyperthermic intrathoracic perfusion chemotherapy in the treatment of MPM. In 2014, he moved to Texas Medical Center as the Chief of Thoracic Surgery, The Olga Keith Wiess Professor of Surgery, Baylor College of Medicine and established the Lung Institute integrating medical and surgical treatment of complex lung diseases.

On a personal note, I got to know Dr. Sugarbaker in September 1995 in Tokyo when we were both invited speakers at an international conference there. He recognised the growing importance of Video Assisted Thoracic Surgery (VATS) and organised the first Minimally Invasive Thoracic Surgery Interest Group (MITSIG) international Symposium, on September 13-14, 1996. He invited me to join the esteemed faculty which gave me the honour and pleasure to meet his wife, Linda. Two years later, I reciprocated and organised the Second MITSIG International Symposium in Hong Kong on November 20-21, 1998. We became good friends, and he visited me at my home when he came to Hong Kong (Figure 2,3). I truly admire and applaud his innovation, perseverance, and stamina in bringing changes to thoracic surgical training in the US and to $\mathrm{BWH}$ under the Harvard Medical School, despite resistance.

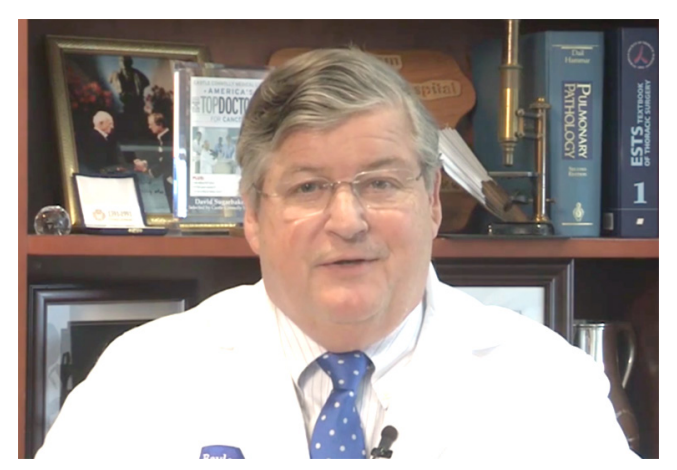

Figure 1 The late David John Sugarbaker, MD (1953-2018). 
Dr. Sugarbaker was an exceptional all rounded leader-a surgical scientist, pioneer, educator, administrator, but above all, a compassionate doctor. He asked me to look after a patient with MPM from Hong Kong whom he operated on, and it was through this patient that I experienced first-hand how meticulous and compassionate he was.

We are greatly saddened to lose a legend, but his spirit lived on through the many surgical leaders he trained. Dr. Sugarbaker, the thoracic surgical community is grateful to you, and thank you for leaving us your legacy.

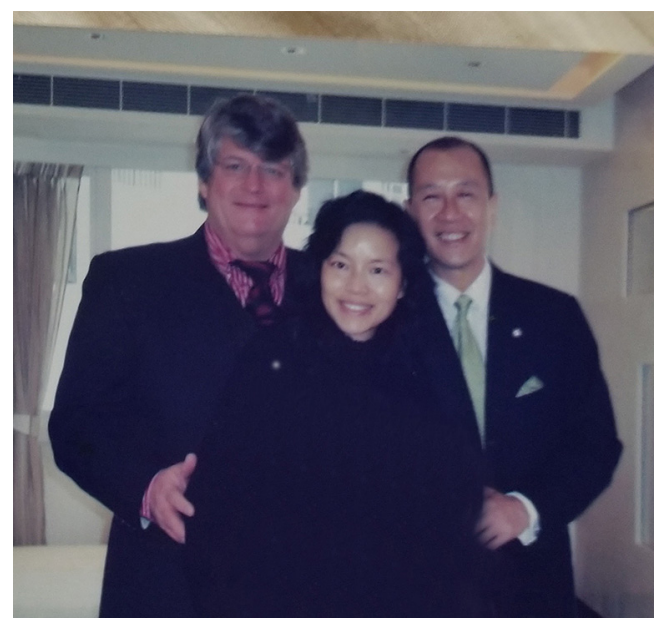

Figure 2 Dr. Sugarbaker visited my home in 2009.

Cite this article as: Yim AP. My last tribute to a friend, a pioneer and legend-Dr. David John Sugarbaker (1953-2018). J Thorac Dis 2019;11(Suppl 14):S1829-S1830. doi: 10.21037/ jtd.2018.09.65

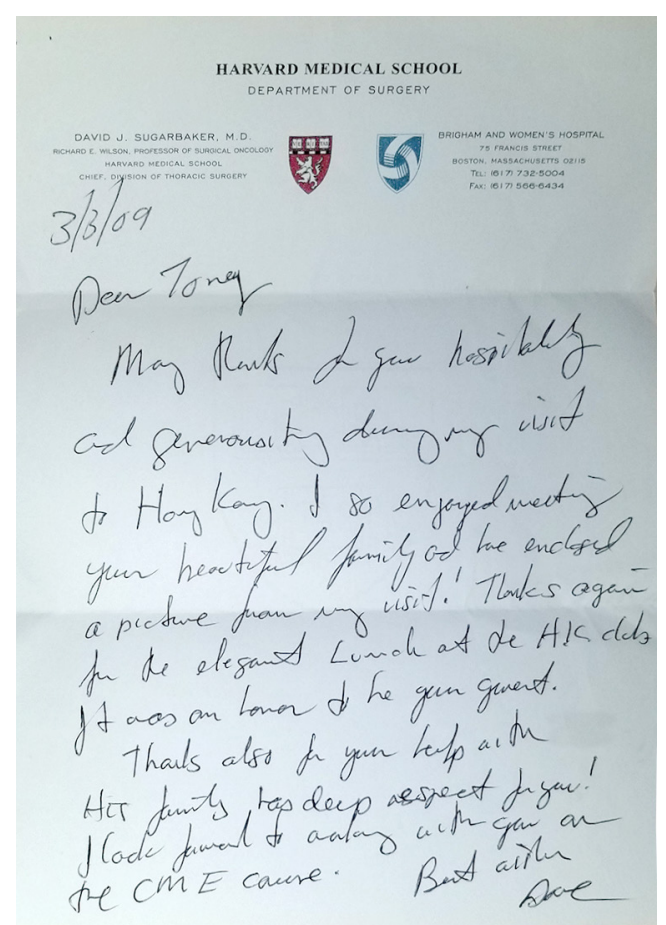

Figure 3 A thank you letter from Dr. Sugarbaker after his visit to Hong Kong in 2009.

Anthony P. C. Yim, MD

Minimally lnvasive Thoracic Surgery Ltd., Hong Kong, China. (Email: yimap@yahoo.com.hk) doi: $10.21037 /$ jtd.2018.09.65

Conflicts of Interest: The author created the cover painting entitled "Huang Shan (Yellow Mountain)", a reinterpretation of a traditional Chinese Landscape using unconventional mixed media on a silver card. The author would like to dedicate this to the late Dr. David J. Sugarbaker in fond memory of him. $53.5 \times 76 \mathrm{~cm}$ (September 2018).

View this article at: http://dx.doi.org/10.21037/jtd.2018.09.65 